\title{
Pareamento de fungos cultivados por diferentes espécies de formigas cortadeiras no Rio Grande do Sul
}

\author{
Fusion of fungi cultivated by different species of cutter ants in Rio Grande do Sul, Brazil
}

\author{
Regina da Silva Borba ${ }^{\text {I* }}$ Alci Enimar Loeck ${ }^{\text {II }}$ Juliana Severo Castelo Branco ${ }^{\text {III }}$ \\ Juliane Bonow ${ }^{\text {III }}$ Antônio Costa de Oliveira ${ }^{\text {III }}$
}

\section{RESUMO}

Este trabalho teve por objetivo estudar a possível ocorrência de heterocariose por meio do pareamento de fungos provenientes de diferentes espécies de formigas cortadeiras coletados em diferentes regiões do Estado do Rio Grande do Sul, utilizando a técnica AFLP. Dez grupos de pareamentos foram realizados, sendo que em dois não ocorreu a fusão das colônias. Após ocorrerem os pareamentos, foram coletados discos de micélio da área de intersecção das colônias e das áreas extremas de pareamento, para a realização da extração do DNA e padronização. Para as reações de PCR, utilizaramse 21 combinações de primers AFLP, dos quais foram selecionados três que apresentaram maior polimorfismo $e$ consistência. Os dados moleculares foram transformados em matriz binária e analisados pelo programa estatístico NTSYS v. 2.1. As três combinações de primers utilizadas geraram 245 bandas polimórficas. A similaridade média dos genótipos variou de 0,03 a 0,18 em todos os pareamentos. A grande distância genética encontrada entre os organismos possivelmente ocorreu por três fatores: a possível ocorrência de heterocariose entre os fungos, a utilização de fungos oriundos de diferentes espécies de formigas e de diferentes regiões. O trabalho sugere que a heterocariose pode representar um importante papel no ciclo de vida deste fungo, uma vez que sua multiplicação é clonal e há ausência de frutificação.

Palavras-chave: compatibilidade vegetativa, marcadores moleculares, variabilidade, AFLP.

\section{ABSTRACT}

This research work had as objective to study the possible heterokaryosis occurrence through the fusion of mushrooms originating from nests of different species of cutter ants collected in different areas of the State of Rio Grande do Sul, using the AFLP technique. Ten fusion groups were accomplished, from which two did not perform a colony coalition. After the fusion occurred, disks of mycelium of the colonies intersection area and fusion external areas were collected, the extraction of DNA and standardization was performed. PCR reactions were tested using 21 AFLP primer combinations, from which three were selected because they presented larger polymorphism and consistence. The molecular data were transformed at binary head office and analyzed by the statistical program NTSYS v. 2.1. The three combinations of primers generated 245 polymorphic bands. The average similarity of the genotypes varied from 0.03 to 0.18 in all the fusions. The large genetic distance found among the organisms possibly happened due to three factors: the possible heterokaryosis occurrence among the mushrooms; the use of mushrooms originating from different species of ants and; from different areas. This work suggests that the heterokaryosis can represent an important role in the life cycle of this mushroom, since it multiplies by clonal propagation and due to the absence of fructification.

Key words: vegetative compatibility, molecular markers, variability, AFLP.

\section{INTRODUÇÃO}

A associação entre as formigas cortadeiras e fungos simbiontes é obrigatória, de tal forma que nenhum dos parceiros poderia sobreviver isoladamente. As formigas inoculam o fungo sobre a matéria vegetal e previnem o crescimento de microorganimos contaminantes, que competem com seu desenvolvimento (HOLLDÖBLER \& WILSON, 1990). O fungo cresce sobre o material vegetal, produzindo

IPrograma de Pós-graduação em Fitossanidade, Universidade Federal de Pelotas (UFPel), Campus Universitário, CP 354, 96010900, Pelotas, RS, Brasil. E-mail: rsborba@pop.com.br.*Autor para correspondência.

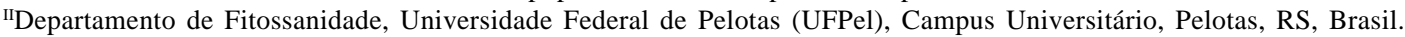

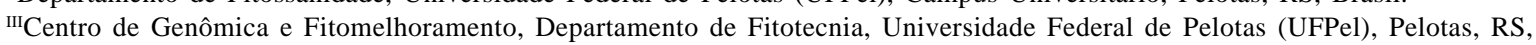
Brasil. 
hifas e gongilídeos que são considerados a principal fonte de nutrientes para as formigas, especialmente para as larvas (QUINLAN \& CHERRETT, 1979).

A análise sistemática desse fungo é dificultada pela grande semelhança morfológica destes organismos no estado vegetativo e pela inexistência, até o momento, de frutificação das culturas em laboratório.

Nesse sentido, informações que possam melhor elucidar a relação simbionte entre a formiga e o fungo e seus mecanismos de evolução são de grande importância para auxiliar na identificação. Além do mais, são importantes para a busca de controles mais eficientes e, para o estudo da filogenia das formigas.

A variabilidade genética é um dos fatores evolutivos dos seres vivos (ALLARD, 1960) e pode ser alcançada pelos fungos por meio de mutação ou recombinação gênica. A mutação pode ser ampliada por meio de um mecanismo denominado heterocariose, fenômeno em que por meio da fertilização ou da anastomose de hifas, dois núcleos distintos podem coexistir na mesma célula sem que haja sua fusão, permitindo aos fungos heterocarióticos uma capacidade de adaptação somática às condições ambientais.

Em fungos heterotálicos, existem os chamados grupos de reação ou compatibilidade sexual, em que os cruzamentos só ocorrem entre indivíduos pertencentes a grupos diferentes, ocorrendo então fusões sexuais somente entre células de talos de diferentes grupos de acasalamento. A heterocariose complementa ou substitui o ciclo sexual, podendo ser a razão pela qual muitos fungos tornaram-se imperfeitos (BERGAMIN FILHO et al., 1995).

O processo de recombinação sexuada ocorre em fungos que apresentam ciclo sexuado. Fungos imperfeitos, como os produzidos pelas formigas cortadeiras, que parecem não apresentar ciclo sexuado, reproduzem-se de forma clonal e, portanto, não apresentam variação devido à recombinação meiótica, então podem recorrer ao ciclo parassexual para criar novas combinações de genes.

Nesse sentido, a determinação do processo ou processos envolvidos na variabilidade de fungos cultivados pelas formigas pode auxiliar na elucidação dos mecanismos de sobrevivência dos fungos nos diferentes ambientes oferecidos pelas formigas cortadeiras.

As primeiras informações sobre os mecanismos de variações nos fungos imperfeitos, indicando a possibilidade de existência de núcleos geneticamente distintos na mesma hifa, foram registradas por HANSEN \& SMITH (1932) em Botrytis cinerea.

O fato de que a heterocariose pode produzir novas raças foi primeiramente demonstrado por NELSON et al. (1955), verificando que o heterocarion resultante das raças 38 e 56 de Puccinia graminis f. sp. tritici era patogênico a cultivar de trigo Kapli Emmer, que era resistente aos seus homocarions constituintes.

Entretanto, parâmetros morfológicos do fungo cultivado por formigas cortadeiras dos gêneros Atta e Acromyrmex foram estudados in vitro por BRANCHER (1993), verificando que estes parâmetros não são confiáveis para a comprovação destas diferenças.

As dificuldades dos ensaios baseados no fenótipo podem ser eliminadas por meio da identificação direta do genótipo por meio de ensaios diagnósticos usando-se marcadores genéticos baseados no DNA (BECKMANN \& SOLER, 1983).

Assim sendo, este trabalho teve por objetivo verificar a ocorrência de heterocariose por meio do pareamento de fungos provenientes de diferentes espécies de formigas cortadeiras coletados em diferentes regiões do Estado do Rio Grande do Sul, usando a técnica AFLP.

\section{MATERIAL E MÉTODOS}

O estudo foi realizado no Laboratório de Mirmecologia do Departamento de Fitossanidade e no Centro de Genômica e Fitomelhoramento do Departamento de Fitotecnia da Faculdade de Agronomia “Eliseu Maciel” (FAEM) da Universidade Federal de Pelotas (UFPel), no ano de 2005. Os fungos foram coletados de diferentes espécies de formigas cortadeiras em diferentes regiões do Estado do Rio Grande do Sul.

As placas de Petri foram inoculadas com discos de meios contendo micélio do fungo utilizandose vasador de quatro milímetros de diâmetro, acomodando-se duas amostras distanciadas entre si em dois centímetros em cada placa. Foram realizados dez grupos de pareamentos, sendo que para cada grupo foram utilizadas quinze repetições: 1. Acromyrmex heyeri (Santa Maria) x Acromyrmex crassispinus (Vacaria); 2. Acromyrmex heyeri (Pelotas) x Acromyrmex heyeri (Santa Maria); 3. Acromyrmex heyeri (Santa Maria) x Atta sexdens piriventris (laboratório); 4. Acromyrmex heyeri (Pelotas) x Acromyrmex lundi (Bento Gonçalves); 5. Acromyrmex ambiguus (Pelotas) x Acromyrmex ambiguus (Bagé); 6. Acromyrmex ambiguus (Pelotas) x Atta sexdens piriventris (laboratório); 7. Acromyrmex crassispinus (Pelotas) x Atta sexdens piriventris (laboratório); 8. Acromyrmex crassispinus (Pelotas) x Acromyrmex

Ciência Rural, v.38, n.5, ago, 2008. 
crassispinus (Vacaria); 9. Acromyrmex laticeps (André da Rocha) x Acromyrmex laticeps (Passo Fundo); 10. Acromyrmex lundi (Pelotas) x Acromyrmex lundi (André da Rocha);

Utilizou-se o meio de cultura de PAGNOCCA et al. (1990) (glucose dez g, cloreto de sódio cinco g, bacto peptona cinco g, extrato de malte dez g, ágar 15g, água destilada 1000mL).

Após a verificação da ocorrência de pareamento, foram coletados discos de micélio da área de intersecção das colônias e das áreas extremas de pareamento, para a realização da extração de DNA. O DNA utilizado nas análises de AFLP (amplified fragment lenght polymorphism) foi extraído de acordo com o protocolo modificado descrito por SAGHAIMAROOF et al. (1984). A quantificação do DNA total foi realizada por eletroforese com gel de agarose $1 \%$ corado com brometo de etídeo (SAMBROOK et al., 1989), por meio da comparação com bandas de concentração conhecida.

A análise de marcadores AFLP foi realizada de acordo com o protocolo descrito por VOS et al. (1995). Foram testadas 21 combinações de iniciadores AFLP, dos quais três apresentaram bandas consistentes ( $\mathrm{C}_{1}$ : E-ACC/M-CTC; $\mathrm{C}_{2}$ : E-AAC/M-CTC; $\mathrm{C}_{3}$ : E-ACG/M-CTT), onde: Ci: i-ésima combinação de iniciadores; E: EcoRI e M: MseI.

Posteriormente, realizou-se a digestão do DNA com enzimas de restrição, a ligação de adaptadores específicos aos sítios de restrição, a reação de pré-amplificação e a amplificação seletiva com as quatro combinações de primers citadas anteriormente. O programa de amplificação consistiu de um ciclo inicial de desnaturação a $94^{\circ} \mathrm{C}$ por $30 \mathrm{~s}, 65^{\circ} \mathrm{C}$ por $30 \mathrm{~s}$ para o anelamento dos iniciadores e $72^{\circ} \mathrm{C}$ por 90 s para extensão. A temperatura de anelamento foi diminuída em $1^{\circ} \mathrm{C}$, por onze ciclos, até atingir a temperatura de $56^{\circ} \mathrm{C}$, sendo realizados mais 23 ciclos com a temperatura de anelamento.

Para visualizar os fragmentos amplificados e separados eletroforeticamente em gel desnaturante de poliacrilamida (6\%), foi utilizado o protocolo de coloração à base de nitrato de prata, descrito por CRESTE et al. (2001).

Os dados de presença/ausência de bandas obtidos na análise de AFLP dos genótipos estudados permitiram o cálculo da similaridade genética entre todos os pares de genótipos, com o auxílio do programa NTSYS pc 2.1 (ROHLF, 2000). Para o cálculo da similaridade genética $\left(\mathrm{S}_{\mathrm{ij}}\right)$, foi utilizado o coeficiente de Dice (DICE, 1945), conforme a equação: $S_{i j}=2 N_{i j} /\left(N_{i}+\right.$ $\mathrm{N}_{\mathrm{j}}$ ); onde: $\mathrm{N}_{\mathrm{ij}}=$ número de bandas presentes em ambos os genótipos i e j; $\mathrm{N}_{\mathrm{i}}=$ o número de bandas presentes no genótipo $\mathrm{i}$, e $\mathrm{N}_{\mathrm{j}}$ = o número de bandas presentes no genótipo $\mathrm{j}$.

Com base na matriz de similaridade, foi construído um dendrograma pelo método de agrupamento da distância média (UPGMA). O ajuste entre a matriz de dissimilaridade e o dendrograma foi estimado pelo coeficiente de correlação cofenética (r; SOKAL \& ROHLF, 1962) por meio do programa computacional NTSYS pc 2.1 (ROHLF, 2000).

\section{RESULTADOS E DISCUSSÃO}

Dos dez grupos de pareamentos apenas nas combinações A. heyeri (Santa Maria) x A. sexdens piriventris (laboratório) e A. heyeri (Pelotas) x A. lundi (Bento Gonçalves) não ocorreu pareamento de suas colônias, mostrando não serem compatíveis por algum motivo, devido à incompatibilidades no núcleo ou na mitocôndria (KUES, 2000). Similarmente, no trabalho de ROCA et al. (2003), apenas $20 \%$ dos conídios de Colletotrichum formaram anastomose e, conseqüentemente, heterocariose. Quando dois isolados de um fungo são vegetativamente compatíveis, suas hifas podem fazer contato, fusão e formação de heterocariose (OLIVEIRA \& COSTA, 2003). Isso aconteceu nos outros oito grupos de pareamentos deste trabalho. A heterocariose ou sua reação contrária de incompatibilidade já foi observada em muitos fungos em que a fase sexual não é conhecida e a troca de material genético se dá por mecanismos parassexuais.

A interação compatível (heterocariose) se caracterizou pelo aparecimento de micélio aéreo denso na linha de contato entre as duas colônias. Já nas colônias que não foram compatíveis, formou-se uma linha bem definida, separando-as. Observa-se que, nos dois grupos onde não houve pareamento de suas colônias, o fungo da espécie $A$. heyeri estava presente, podendo ter uma relação com o substrato utilizado, já que de todas as espécies envolvidas no trabalho, esta forrageia exclusivamente folhas estreitas (FOWLER et al., 1989; MAYHÉ-NUNES, 1991).

As três combinações de primers utilizadas geraram um total de 245 bandas polimórficas de DNA. $\mathrm{O}$ número de bandas geradas por combinação de primers foi de 76 (E-ACC/M-CTC), 62 (E-AAC/M-CTC) e 107 (E-ACG/M-CTT).

Utilizando a similaridade média como ponto de corte $(0,09)$, foi possível verificar a formação de seis grupos distintos (Figura 1). O grupo VI abrangeu a maioria dos genótipos, sendo que dos oito pareamentos realizados, seis deles ficaram incluídos neste grupo, juntamente com um dos genitores do 


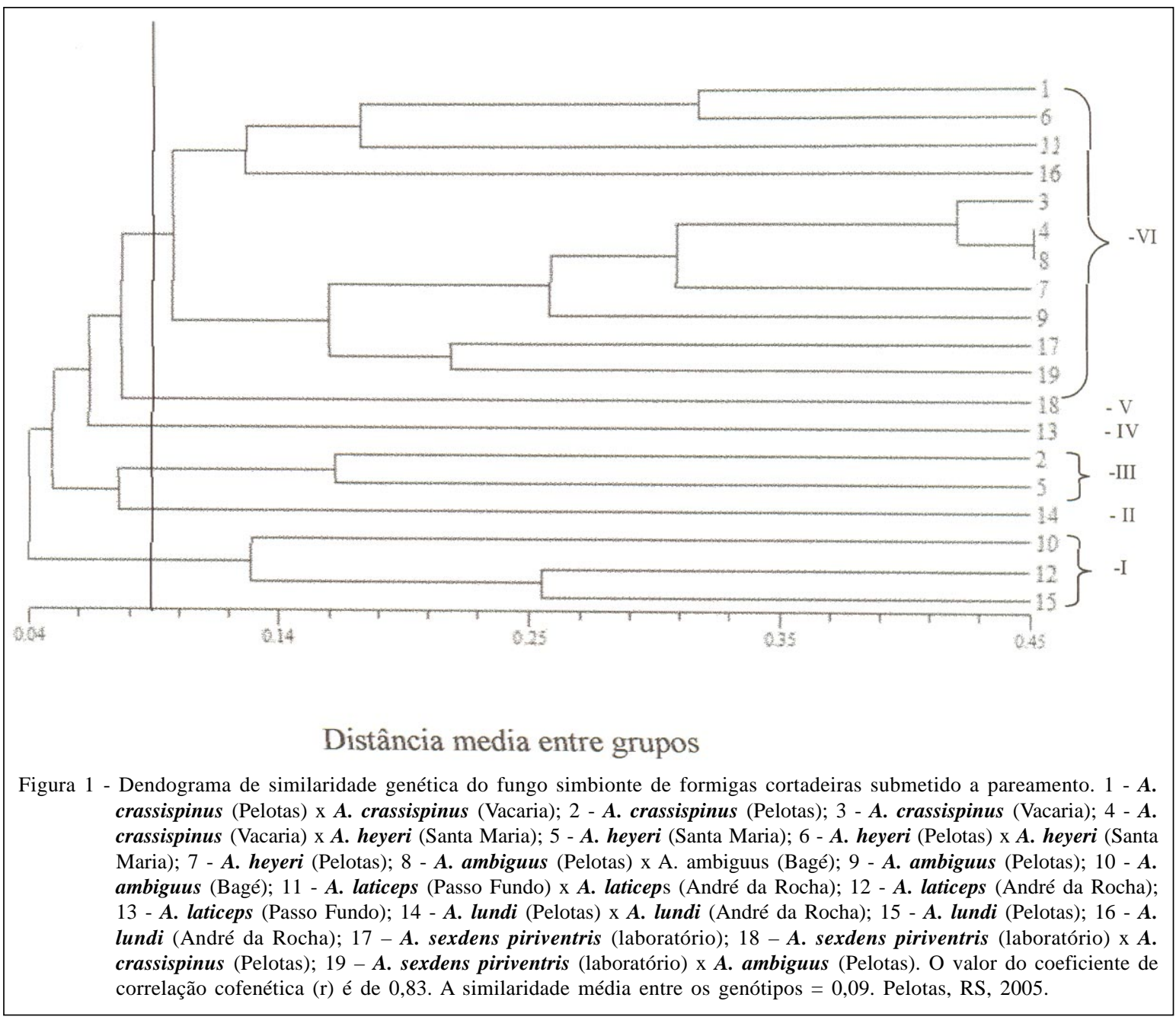

pareamento. Isso demonstra que o resultado da heterocariose sempre resultou na proximidade de um dos pais.

O grupo V ficou isolado dos demais e inclui apenas o pareamento $A$. sexdens piriventris (laboratório) x A. crassispinus (Pelotas), provavelmente pelo fato de o fungo ser resultado do cruzamento de dois gêneros diferentes de formigas e também porque existe uma confusão em torno da caracterização genética do fungo de $\boldsymbol{A}$. crassispinus, pois, no trabalho de LOECK et al. (2003), a similaridade genética do fungo A. crassispinus coletado no município de Caibaté (Noroeste do RS) foi mais próxima dos fungos cultivados por A. ambiguus (coletados em diferentes regiões) do que os fungos cultivados pela mesma espécie (A. crassispinus) no município de Guaíba (Leste do RS)

Assim também ocorreu com o pareamento A. Iundi (Pelotas) x A. lundi (André da Rocha), que é o único representante do grupo II. Este pode ter ficado isolado dos demais devido ao hábito dessa espécie ser diferenciado, já que estas formigas constroem ninhos subterrâneos, enquanto que as demais apresentam ninhos mais superficiais (LOECK \& GRÜTZMACHER, 2001).

No entanto, o grupo que representa o maior número de pareamentos é o VI, que pode ser dividido em dois subgrupos: VIa (um, seis, onze e 16) e VIb (três, quatro, oito, nove e 17). Ao observar os pareamentos com base na localização dos genótipos isolados, é possível verificar a causa da grande variabilidade genética. Por exemplo, os pareamentos que formaram novos grupos foram 14 (II), que é o pareamento de 15(I) x 16 (VIa), 18 (V)=17 (VIb) x dois (III) e onze (VIa)=13(IV) x 12 (I). Os pareamentos que se mantiveram no grupo de um dos genótipos originais foram sempre agrupados no grupo VI: um (VIa)= dois (III) x três (VIb), quatro (VIb)= três (VIb) x cinco (III), seis $(\mathrm{VIa})=$ sete $(\mathrm{VIb}) \mathrm{x}$ cinco $(\mathrm{III})$ e oito $(\mathrm{VIb})=$ nove (VIb) x dez (I). O pareamento 19 (VIb) = 17 (VIb) x nove

Ciência Rural, v.38, n.5, ago, 2008. 
(VIb) foi agrupado junto com os genótipos isolados, o que seria esperado, com base na similaridade genética entre 17 e nove.

Os resultados sugerem que os heterocárions formados pelos genótipos três, sete e nove (A. crassispinus - Vacaria; A. heyeri - Pelotas e A. ambiguus - Pelotas) tendem a manter-se similares aos mesmos, sugerindo uma maior agressividade destes fungos, traduzindo-se numa retenção maior de seus cromossomos em relação ao outro componente da fusão. Isso pode ser observado em produtos de fusão conhecidos como radiation hybrids (WALTER \& GOODFELLOW, 1993). Entretanto, estes resultados precisam ser confirmados em maior detalhe para dar suporte a esta hipótese.

A grande distância genética encontrada entre os organismos possivelmente ocorreu devido a três fatores: a ocorrência de heterocariose entre os fungos, a coevolução dos fungos oriundos das diferentes espécies de formigas e, as diferenças sazonais, podendo estar relacionado com a exploração de diferentes espécies vegetais pelas formigas.

As análises de compatibilidade vegetativa não são apropriadas para determinar diferenças biológicas entre as espécies ou acessar diferenças que ocorrem ao nível de espécie e sim para avaliar diferenças genotípicas (LESLIE, 1996).

Avaliando a compatibilidade vegetativa de Fusarium solani patogênicos e não-patogênicos ao feijoeiro e à soja, OLIVEIRA \& COSTA (2003) encontraram compatibilidade vegetativa entre os isolados. Se em alguma circunstância estes isolados estivessem no mesmo hospedeiro ao mesmo tempo, a heterocariose e a complementação de alelos poderiam ocorrer. Eles demonstraram, também, a formação de heterocariose entre dois isolados de formae speciales diferentes e que esta perfeita compatibilidade pode ser uma justificativa para a existência de isolados que são patogênicos a ambas as culturas.

A baixa similaridade genética encontrada entre os fungos concorda com os dados de BRANCHER (1993), que ao analisar variações genotípicas dos fungos de diferentes isolados de $\boldsymbol{A}$. sexdens piriventris, A. heyeri, A. ambiguus e A. crassispinus, por meio de eletroforese, observou baixos índices de similaridade genética obtidos entre os isolados provenientes das diferentes espécies de formigas, bem como da mesma espécie, confirmando a alta variabilidade genotípica existente entre os isolados.

Esta alta variabilidade genética pode estar relacionada também com o ambiente, assim como no trabalho de DOHERTY et al. (2003), que ao analisar isolados de fungos cultivados por Atta cephalotes de ninhos de duas localidades geograficamente distantes, Panamá e Trinidad, por meio da técnica RAPD, observaram considerável variação genética entre os fungos dos diferentes locais, com uma similaridade média de 36\%.; Já para os isolados oriundos do Panamá e de Trinidad, as similaridades médias foram de 79,6\% e $72,1 \%$, respectivamente. Os autores sugeriram que essas diferenças genéticas resultam de mutação, dispersão, ou ainda, seleção.

\section{CONCLUSÃO}

Este trabalho sugere que a heterocariose pode representar um importante papel no ciclo de vida deste fungo, uma vez que sua multiplicação é vegetativa e não ocorre frutificação. Nos dois grupos em que não houve pareamento, os isolados podem ter sofrido alterações devido a variações genéticas em função do ambiente e/ou do substrato vegetal oferecido pelas formigas.

\section{REFERÊNCIAS}

ALLARD, R.W. Principles of plant breeding. New York: John Wiley \& Sons, 1960. p.335-339.

BECKMANN, J.S.; SOLER, M. Restriction fragment length polymorphisms in genetic improvement: Methodologies, mapping and costs. Theoretical and Applied Genetics, v.67, p.35-43, 1983.

BERGAMIN FILHO, A. et al. Manual de fitopatologia. São Paulo: Ceres, 1995. 919p.

BRANCHER, N. Avaliação eletroforética e morfológica do fungo cultivado pelas formigas cortadeiras dos gêneros Atta e Acromyrmex. 1993. 58f. Dissertação (Mestrado em Agronomia - Área de Concentração em Fitossanidade) - Faculdade de Agronomia "Eliseu Maciel” UFPel.

CRESTE, S. et al. Detection of single sequence repeat polymorphism in denaturing polyacrylamide sequencing gels by silver staining. Plant Molecular Biology Reporter, v.19, p.1-8, 2001.

DICE, L.R. Measures of the amount of ecological association between species. Ecology, v.26, n.3, p.297-307, 1945.

DOHERTY,K.R. et al. Random amplified polymorphic DNA markers reveal genetic variation in the symbiotic fungus of leaf-cutting ants. Mycologia, v.95, n.1, p.19-23, 2003.

FOWLER, H.G. et al. A pest is a pest is a pest? The dilemma of neotropical leaf-cutting ants: keystone taxa of natural ecosystems. Environmental Manage, v.13, n.6, p.671-675, 1989.

HANSEN, H.N.; SMITH, R.E. The mechanism of variation in the imperfect fungi, Botrytis cinerea. Phytopathology, v.22, p.953-964, 1932.

Ciência Rural, v.38, n.5, ago, 2008. 
HÖLLDOBLER, B.; WILSON, E.O. The ants. Cambridge: Harvard University, 1990. 732p.

KÜES, U. Life history and developmental processes in the Basidiomycete Coprinus cinereus. Microbiology and Molecular Biology Reviews, v.64, n.2, p.316-353, 2000.

LESLIE, J.F. Fungal vegetative compatibility - Promises and prospects. Phytoparasitica, v.24, n.1, p.3-6, 1996.

LOECK, A.E.; GRÜTZMACHER, D.D. Ocorrência de formigas cortadeiras nas principais regiões agropecuárias do Estado do Rio Grande do Sul. Pelotas: UFPel, 2001. 147p.

LOECK, A. E. et al. Comparação de fungos cultivados por formigas do gênero Acromyrmex em diferentes localidades no Estado do Rio Grande do Sul através de Marcadores Moleculares tipo ISSR. In: SIMPÓSIO DE MIRMECOLOGIA, 16., 2003 Florianópolis-SC. Anais... Florianópolis: UFSC, 2003. p.252253.

MAYHÉ-NUNES, A.J. Estudo de Acromyrmex (Hymenoptera, Formicidae) com ocorrência constatada no Brasil: subsídios para uma análise filogenética. 1991. 122f. Dissertação (Mestrado em Entomologia) - Universidade Federal de Viçosa, Viçosa, MG.

NELSON, R.R. et al. Hetocaryosis as a basis for variation in Puccnia graminis var. tritici. Phytopathology, v.45, p.639643, 1955.

OLIVEIRA, V.C. de; COSTA, J.L.S. da. Compatibilidade vegetativa de nit-mutantes de Fusarium solani patogênicos e não-patogênicos ao feijoeiro e à soja. Fitopatologia Brasileira, v.28, n.1, p.89-92, 2003.
PAGNOCCA, F.C. et al. Toxicity of sesame extracts to the symbiotic fungus of leaf cutting ants. Bulletin of Entomological Research, v.80, p.349-352, 1990.

QUINLAN, R.J.; CHERRETT, J.M. The role of fungus in the diet of the leaf-cutting ant Atta cephalotes (L.). Ecological Entomology, v.4, p.151-160, 1979.

ROCA, M.G. et al. Conidial anastomosis tubes in Colletotrichum. Fungal Genetics and Biology, v.40, p.138-145, 2003.

ROHLF, J.F. NTSYS - pc: Numerical taxonomy and multivariate analysis System. Version 2.1 Exeter Software. Setauket, NY, 2000 .

SAGHAI-MAROOF, M.A. et al. Ribosomal DNA spacer length polymorphism in barley: Mendelian inheritance, chromosome location and population dynamics. Proceedings of the National Academy of Sciences of the U.S.A, v.89, n.2, p.1477-1481, 1984.

SAMBROOK, J. et al. Molecular cloning: a laboratory manual. 2.ed. New York: Cold Spring Laboratory, 1989. V.9, p.16-23.

SOKAL, R.R.; ROHLF, F.J. The comparison of dendrograms by objective methods. Taxon, v.11, n.1, p.30-40, 1962.

VOS, P. et al. AFLP: a new technique for DNA fingerprinting. Nucleic Acids Research, v.23, p.4407-4414, 1995.

WALTER, M.A.; GOODFELLOW, P.N. Radiation hybrids: irradiation and fusion gene transfer. Reviews, v.9, n.10, p.352356, 1993 